Revue d'histoire de l'Amérique française

REVUE D.HISTOIRE DE L'AMÉRIQUE FRANÇAISE

\title{
Mgr de Saint-Vallier et la dévotion à Sainte-Anne
}

\section{Guy Plante}

Volume 24, numéro 3, décembre 1970

URI : https://id.erudit.org/iderudit/302991ar

DOI : https://doi.org/10.7202/302991ar

Aller au sommaire du numéro

Éditeur(s)

Institut d'histoire de l'Amérique française

ISSN

0035-2357 (imprimé)

1492-1383 (numérique)

Découvrir la revue

Citer cette note

Plante, G. (1970). Mgr de Saint-Vallier et la dévotion à Sainte-Anne. Revue

d'histoire de l'Amérique française, 24(3), 406-408.

https://doi.org/10.7202/302991ar d'utilisation que vous pouvez consulter en ligne.

https://apropos.erudit.org/fr/usagers/politique-dutilisation/ 


\section{MGR DE SAINT-VALLIER ET LA DÉVOTION À SAINTE-ANNE}

Guy Plante, P.M.É.

Mgr Jean-Baptiste de Saint-Vallier s'impose comme le pasteur qui a le plus contribué à former l'âme religieuse canadienne sous le régime français. Le prestige, d'ailleurs bien mérité de son prédécesseur, a fait oublier les vigoureuses orientations pastorales du deuxième évêque de Québec: pendant ses quarante ans d'épiscopat (1688-1727) il a convoqué les quatre premiers synodes de l'Eglise canadienne, adressé de nombreux mandements, ordonnances, lettres pastorales, publié le premier Catéchisme et le premier Rituel canadiens, prolongeant ainsi son influence durant près de deux siècles. ${ }^{1}$

1 Voir: F. Porter, Catéchisme du diocèse de Québec, 1702, avec présentation, notes explicatives et commentaires par Fernand Porter (Montréal, Ed. Franciscaines, 1958), 544. 
La pensée théologique de ce prélat, encore mal inventoriée, ${ }^{2}$ réserve de précieuses découvertes à ceux qui veulent retracer les traits caractéristiques de l'Eglise canadienne. Le document ${ }^{3}$ ici présenté atteste, sans équivoque, une dévotion qui a nourri la piété de quelques générations de Canadiens. Mgr de SaintVallier avait déjà signalé, en 1688, dans sa lettre sur l'Estat present de l'Eglise et de la Colonie Françoise dans la Nouvelle France, la grande joie éprouvée au Port-Royal "de voir le jour de Sainte Anne, la ferveur avec laquelle la pluspart receurent les Sacremens". ${ }^{4}$ D'ailleurs, écrivait-il dans le même document, la paroisse Ste-Anne sur la côte de Beaupré, était un "lieu de pelerinage où l'on va toute l'année". ${ }^{5}$ Le témoignage que l'évêque apporte dix-huit ans avant sa mort prolonge ces constatations et les affermit.

Nous Jean Par La grace de Dieu et du $S^{t}$ Siege Apostolique Evêque de Quebec a nos tres chers freres en Nôtre Seigneur, les prebtres Seculiers et Reguliers de Ville marie et à Messieurs les officiers, et habitants de la ditte Ville Salut et Benediction en Nôtre Seigneur.

Dieu nous ayant rendu temoins d'une chose aussy extraordinaire qua paru lêtre la guerison de la Demoiselle Catherine dupré par l'intercession de la grande $S^{\text {te }}$ Anne, semble exiger de vous une recognoissance proportionée a la marque evidente et publique de la puissance souveraine et sur naturelle qu'il a voulu faire paroitre dans cette occasion pour animer vôtre foy et augmenter vôtre confiance a la grande sainte qui la obtenuë de Dieu, C'est ce qui vous doibt obliger a redoubler vôtre dévotion a cette grande sainte et grande mere de Jesus pour obtenir par

2 Voir: A. Rambaud, "Jean-Baptiste de La Croix de Chevrières de Saint-Vallier", Dictionnaire biographique du Canada (Québec, 1969), II: 342-349. Le Père H. Bibeau a publié: "Le climat moral en Nouvelle-France à l'arrivée de Mgr de Saint-Vallier", $R H A F, 22$ (1968): 415-428; "La pensée mariale de Mgr de Saint-Vallier", SCHEC, 33 (1966) : 17-23. Noter un volume actuellement sous presse aux Editions Duculot: G. Plante, $A u x$ origines du rigorisme canadien: Mgr de Saint-Vallier et le refus de l'absolution. Ce volume paraîtra en 1971 .

3 Ce document est à l'Université de la Colombie Britannique (Special Collections Division, no 220) et porte la note suivante: Canada: A fine D.S.3 pages, 4 to. "Quebec, June 20, 1726", by "JEAN, EVEQUE DE QUEBEC" (Jean, Bishop of Quebec). With fine seal; etc. - A very interesting early Canada item. $R A R E$.

4 Estat present de l'Eglise et de la Colonie Françoise dans la Nouvelle France par M. l'Evêque de Quebec (Réimpression: S.R. Publishers Limited, Johnson Reprint Corp., Mouton \& Co., N.V., 1965), 99.

5 Ibidem, 55. 
son moyen des faveurs encore plus esentielles pour vos ames que celle qu'elle a fait a cette chere infirme pour son corps, C'est pourquoy nous vous invitons a rendre de tres humbles et publiques actions de graces a Dieu par ce premier et visible bienfait qui vous met en etat de recognoitre la puissance de Jesus et l'amour de cette sainte protectrice qui a tant fait de bien par le passé a cette colonie, et qui continuë touts les jours a luy en tant faire, que nous pouvons dire que nous luy debvons tout, redevables que nous Luy sommes de la conservation de ce pays qu'elle a si solemnellement defendu et protegé, ne cessons chaque jour de luy en faire nos humbles remerciments et de la presser de ne nous point abandonner tout le temps de nôtre perelinage (sic) sur la terre, C'est a quoy nous vous invitons en qualité de Pere et de pasteur qui vous recommande continuellement a ce prince des Pasteurs dans l'amour et dilection duquel nous debvons touts vivre et mourir ainsi soit-il. Donné a quebec sous nôtre seing celuy de nôtre secretaire et scellé du sceau de nos armes ce $20^{e}$ juin, 1726.

Jean eveque de quebec

(sceau)

Par Monseigneur

Tessié 